\title{
Inhaled corticosteroid treatment for 6 months was not sufficient to normalize phagocytosis in asthmatic children
}

\author{
Carmen Lívia Faria da Silva-Martins ${ }^{1,2,3}$, Shirley Claudino Couto $^{1}$ and Maria Imaculada Muniz-Junqueira**
}

\begin{abstract}
Background: Corticosteroids are the first-line therapy for asthma; however, the effect of corticosteroids on the innate immune system remains unclear. This study's objective was to evaluate the effect of inhaled corticosteroid therapy (ICT) on phagocytic functions.

Methods: To evaluate the impact of ICT, the phagocytosis of Saccharomyces cerevisiae by blood monocytes and neutrophils and the production of superoxide anions were assessed before and after three and six months of ICT treatment in 58 children with persistent asthma and 21 healthy controls.

Results: We showed that the phagocytic capacity of monocytes and neutrophils that occurred via pattern recognition receptors or was mediated by complement and immunoglobulin receptors in asthmatic children before treatment was significantly lower than in healthy controls ( $p<0.05$, Mann-Whitney test) and was not influenced by the severity of the clinical form of the disease. Although there was clinical improvement with treatment, ICT for 6 months was not sufficient to normalize phagocytosis by the phagocytes. Superoxide anion production was also decreased in the asthmatic children before treatment, and ICT normalized the $\mathrm{O}^{-}$production only for children with mild persistent asthma when assessed at baseline but caused this function to decrease after stimulation ( $p<0.05$, Kruskal-Wallis test).

Conclusions: Our data suggest that an immunodeficiency in phagocytes remained even after treatment. However, this immunodeficiency does not appear to correspond with the clinical evolution of asthma because an improvement in clinical parameters occurred.
\end{abstract}

Keywords: Asthma, Immunodeficiency, Neutrophils, Monocytes, Oxygen radical production, Phagocytosis

\section{Introduction}

Asthma is a serious global health problem throughout the world. An estimated 300 million individuals are affected by this disease [1], which is the most common chronic disease of childhood [2].

Corticosteroids are the first-line drugs for asthma therapy and are by far the most effective anti-inflammatory treatment [3], resulting in marked reductions in asthma morbidity and mortality $[4,5]$.

The goals of asthma treatment are to control the clinical symptoms for extended periods, prevent asthma

\footnotetext{
* Correspondence: mimjunqueira@unb.br

'Laboratory of Cellular Immunology, Pathology, Faculty of Medicine, Campus Darcy Ribeiro, Asa Norte, University of Brasilia, Brasilia, DF 70.910-900, Brazil
} Full list of author information is available at the end of the article exacerbations, maintain pulmonary function, and control airway inflammation [6]. Inhaled corticosteroids (ICS) are very effective in controlling asthma symptoms in patients of all ages and severities and may prevent irreversible airway changes $[4,5,7]$. However, corticosteroid treatment also has several side effects [8] and may influence the functions of immune system cells $[9,10]$.

Children with asthma have an increased frequency of pulmonary infections, and it is possible that alterations in the function of phagocytes, which are engaged in the first line of defense against pathogens, may play a role in these infections [11]. Monocyte chemotaxis in vitro is inhibited by high concentrations of steroids [12]. In addition, corticosteroids affect nitric oxide production, total free radical production, and nitric oxide synthase activity in the monocytes

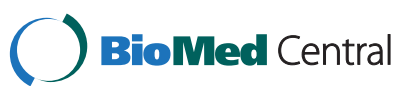


of asthmatic patients [10]. Furthermore, there are reports of defective phagocytosis of pathogens in asthma patients [13]. Phagocytosis by alveolar macrophages is impaired in children with poorly controlled asthma [11], and oxidative stress is emerging as a common mechanism that may alter both macrophage and neutrophil functions [13].

The influence of ICS treatment on phagocyte functions in asthmatic children remains unclear. Either the treatment or the disease may influence phagocyte functions directly or through several cytokines and substances produced as part of the altered immune response in affected individuals. Therefore, the objective of this study was to evaluate the undetermined influence of ICS treatment on the phagocytic function of monocytes and neutrophils from asthmatic children after 3 and 6 months of therapy and to compare phagocytosis and the production of toxic oxygen radicals in asthmatic children and healthy control subjects. This study may shed light on the effects of corticosteroids on cells of the innate immune system in asthmatic children and may improve the understanding of the mechanism of action of this drug. It was showed that the phagocytic capacity of monocytes and neutrophils that occurred via pattern recognition receptors or was mediated by complement and immunoglobulin receptors in asthmatic children before treatment was significantly lower than in healthy controls and inhaled corticosteroid treatment for 6 months was not sufficient to normalize phagocytosis in asthmatic children.

\section{Methods}

\section{Study groups}

One author (CLFSM), a pediatric pneumologist, conducted the clinical evaluation of all control and asthmatic children and sequentially selected and screened 58 children who were seen in the pediatric asthma outpatient clinic at Brasilia University Hospital for enrolment in this study. The children were placed in the following groups: a group of 58 outpatient asthmatic children with variable disease severity (27 girls and 31 boys; $7.6 \pm 3.4$ years) from whom blood was collected before, at 3 months, and at 6 months of inhaled corticosteroid therapy. Asthma was classified as mild, moderate, or severe persistent disease by the frequency of the symptoms, presence of nocturnal asthma, frequency of acute exacerbations, medications required for control, physical activity limitations, or altered pulmonary functioning [14]. Twenty-four (41.3\%) asthmatic children had mild asthma, $20(34.5 \%)$ children had moderate asthma and 14 (24.1\%) had severe persistent asthma. A group of 21 healthy children (12 girls and 9 boys; $10.7 \pm 2.10$ years) without the disease and without a personal or familial history of allergy comprised the control group. At the time of clinical examination, peripheral blood was collected to assess phagocytosis and superoxide anion production.

The exclusion criteria were as follows: children $<2$ years or $>18$ years, any other clinically significant pulmonary disease or other disease, those who presented with any condition that might alter the function of the immune system, any children taking medication other than asthma treatment, and any children that had previously used inhaled corticosteroids, or that used oral corticosteroids in the last 6 months.

During the first evaluation, the group of asthmatic children was assessed for the severity of asthma, asthma control test (ACT), peak expiratory flow (PEF), and body mass index (BMI). The ACT was administered to children aged $4-11$ years ( 7 answers) and $>12$ years ( 5 answers). The test was adapted for children $<4$ years, with the mother responding to the questions. The children were considered clinically controlled (ACT $\geq 25$ ), partially controlled $(\mathrm{ACT}=20-24)$ or uncontrolled $(\mathrm{ACT}<20)[15]$.

The PEF value was recorded as the best of three forced expirations by means of a peak flow meter and expressed as the percentage of predicted of normal values for height and sex values for children $\geq 100 \mathrm{~cm}$. In seven children with mild persistent asthma (mPA), one child with moderate persistent asthma (MPA) and three with severe persistent asthma (SPA) the PEF were not assessed. All these children younger than 5 years had familial history of asthma. The thresholds of PEF used to severity evaluation were: $\mathrm{mPA}$ $\geq 80 \%$ predicted value, $\mathrm{MPA}=60-80 \%$ predicted value, and SPA $\leq 60 \%$ predicted value.

BMI was assessed to exclude any possible influence of child nutritional status on phagocyte functions.

During the second (3 months) and third (6 months) clinical follow-up visits, the children were assessed with the ACT, PFE and BMI.

The children were treated with ICS. A long-acting $\beta_{2}$-agonist (LABA) was added when necessary to control symptoms. All 24 children with mild persistent asthma (mPA), 10 children $<4$ years with moderate persistent asthma (MPA) and 5 children $<4$ years with severe persistent asthma (SPA) received monotherapy with $250 \mu \mathrm{g}$ beclomethasone dipropionate twice day. Eight children with MPA and three with SPA received budesonide + formoterol $6 / 200 \mu \mathrm{g}$ twice day and 1 children with SPA received $12 / 400 \mu \mathrm{g}$ twice day. Two children with MPA and five children with SPA received fluticasone propionate + salmeterol 25/125 $\mu \mathrm{g}$ twice day (Table 1).

Peripheral blood was collected from control and asthmatic children who had fasted for $>12$ hours prior to their blood being drawn. Hemogram (Cell-dyn 3.700) was automatically assessed.

The Human Research Ethical Committee of the School of Medicine of the University of Brasilia approved the experimental protocol (process no. 02/2007).

All parents provided formal informed consent for their child's participation in this study. 
Table 1 Clinical characteristics of healthy controls and asthmatic children before inhaled corticosteroid therapy showing mild, moderate and severe persistent asthma

\begin{tabular}{|c|c|c|c|c|c|}
\hline Parameters & $\begin{array}{l}\text { Normal } \\
\text { control }\end{array}$ & $\begin{array}{l}\text { Mild persistent } \\
\text { asthma }\end{array}$ & $\begin{array}{c}\text { Moderate persistent } \\
\text { asthma }\end{array}$ & $\begin{array}{c}\text { Severe persistent } \\
\text { asthma }\end{array}$ & Test $p$ \\
\hline Number & $21 / 78$ & $24 / 58(41.3 \%)$ & $20 / 58(34.5 \%)$ & $14 / 58(24.1 \%)$ & \\
\hline Gender (boys/girls) & $9 / 12$ & $13 / 11$ & $12 / 8$ & $6 / 8$ & Chi-square $p=0.64$ \\
\hline Age (years) (mean $\pm S D)$ & $10.7 \pm 2.1$ & $6.32 \pm 2.99$ & $9.22 \pm 3.33$ & $7.24 \pm 3.53$ & ANOVA* $p<0.05$ \\
\hline Total leukocytes & 7390 & 9720 & 8120 & 8305 & $\begin{array}{c}\text { Kruskal-Wallis } \\
p=0.05\end{array}$ \\
\hline Neutrophils & 3440 & 4150 & 3640 & 4260 & $\begin{array}{c}\text { Kruskal-Wallis } \\
p=0.66\end{array}$ \\
\hline Monocytes & 568 & 568 & 536 & 643 & $\begin{array}{c}\text { Kruskal-Wallis } \\
p=0.57\end{array}$ \\
\hline Eosinophils & 245 & 460 & 635 & 487 & ANOVA $p=0.003$ \\
\hline $\mathrm{BMI}\left(\mathrm{Kg} / \mathrm{m}^{2}\right)($ mean $\pm \mathrm{SD})$ & $43.31 \pm 32.1$ & $51.9 \pm 34.2$ & $47.4 \pm 31.2$ & $63.7 \pm 32.5$ & $\begin{array}{c}\text { Kruskal-Wallis } \\
p=0.29\end{array}$ \\
\hline PEF (\%) (mean $\pm S D)$ & $86.9 \pm 18.6$ & $81.2 \pm 17.3$ & $75.6 \pm 15.3$ & $65.6 \pm 12.0$ & ANOVA $^{* *} p<0.05$ \\
\hline \multicolumn{6}{|l|}{ Treatment ${ }^{* * *}$} \\
\hline ICS (\%) & & $23 / 23(100 \%)$ & $10 / 20(50 \%)$ & 05/14 (35.7\%) & \\
\hline \multicolumn{6}{|l|}{$\mathrm{ICS}+\mathrm{LABA}(\%)$} \\
\hline Budesonide + formoterol & & $0 / 23(0 \%)$ & $08 / 20(40 \%)$ & $04 / 14(28.6 \%)$ & \\
\hline $\begin{array}{c}\text { Fluticasone propionate }+ \\
\text { salmeterol }\end{array}$ & & 0/23 (0\%) & $02 / 20(10 \%)$ & 05/14 (35.7\%) & \\
\hline
\end{tabular}

$B M I$ Body Mass Index (percentile), PEF Peak Expiratory Flow, $m P A$ mild persistent asthma, MPA moderate persistent asthma, SPA severe persistent asthma, $m P A, M P A, S P A$ data before treatment. Beclomethasone dipropionate $=250 \mu \mathrm{g}$ to $500 \mu \mathrm{g} /$ day; Budesonide + formoterol $6 / 200 \mu \mathrm{g}$ or $12 / 400 \mu \mathrm{g}$ twice day; Fluticasone propionate + salmeterol $=25 / 125 \mu \mathrm{g}$ to $50 / 250 \mu \mathrm{g}$ twice day K-W= Kruskal-Wallis + Dunn's method; * mPA and SPA $<$ C; ${ }^{*}$ SPA $<$ C;

*** Treatment followed GINA.

\section{Phagocytosis test}

Phagocytosis of Saccharomyces cerevisiae was adapted from a previously described technique [16]. Briefly, $40 \mu \mathrm{L}$ samples per marked area of heparinized whole peripheral blood obtained from each subject were placed on duplicate slides containing 8 areas that were each $7-\mathrm{mm}$ in diameter and incubated in a humidified chamber for $45 \mathrm{~min}$ at $37^{\circ} \mathrm{C}$. The slides were then rinsed with $0.15 \mathrm{M}$ phosphate-buffered saline (PBS) (pH 7.2) at $37^{\circ} \mathrm{C}$ to remove non-adherent cells. Adherent cells (12,534 $\pm 5,050$ cells/marked area; $5.63 \pm 0.85 \%$ monocytes and $93.5 \pm 1.08 \%$ neutrophils) (viability $>98 \%$ ) were incubated with a suspension of $2.5 \times 10^{5} \mathrm{~S}$. cerevisiae in $20 \mu \mathrm{L}$ Hanks-Tris solution (Sigma Co., St Louis, MO, USA) (pH 7.2) containing $10 \%$ heat-inactivated fetal calf serum (FCS) (Gibco/ Invitrogen, Grand Island, NY, USA) for $30 \mathrm{~min}$ in a humidified chamber at $37^{\circ} \mathrm{C}$. The slides were then rinsed with $0.15 \mathrm{M} \mathrm{PBS}$ at $37^{\circ} \mathrm{C}$ to eliminate non-phagocytosed $S$. cerevisiae, and the final wash step was performed with $30 \%$ FCS in Hanks-Tris solution. The slides were fixed with methanol and stained with $10 \%$ Giemsa stain. The number of $S$. cerevisiae that were phagocytosed by either 200 monocytes or 200 neutrophils in individual preparations was assessed by light microscopy. The phagocytic index was calculated as the mean number of phagocytosed $S$. cerevisiae per phagocytosing monocyte or neutrophil multiplied by the percentage of these cells engaged in phagocytosis.

The internalization of particles by phagocytes occurs via receptors. When phagocytosis occurs via patternrecognition receptors, the phagocyte recognizes directly conserved pattern molecular in the surface of the particle to be phagocytosed. When phagocytosis is facilitated by opsonins, the ingestion occurs via receptors to components of complement or via receptors to FcIgG. Saccharomices cerevisiae (Baker's yeasts) suspensions were prepared according to a previously described technique [16] to assess phagocytosis via pattern-recognition receptors and facilitated by opsonins. Yeasts were used with or without previous incubation with fresh serum from the donor. In the former case, yeast cells were considered sensitized, because they were opsonized by complement molecules and antibodies in serum. These molecules adhere on yeast surface and will be recognized by their neutrophil and monocyte receptors (CR1, CR3 and FcR) during the process respective of phagocytosis [16]. Yeast cells that were not pre-incubated with fresh serum from the donor, but were incubated with fetal calf serum, were considered as non-sensitized, because they were non-opsonized and their phagocytosis occurs via the pattern-recognition receptors (PRRs) of neutrophils and monocyte [17]. For opsonization, the 
S. cerevisiae were sensitized by incubation at $37^{\circ} \mathrm{C}$ for 30 min with $10 \%$ fresh serum from the donor in Hanks-Tris solution. The yeast cells that were pre-incubated with inactivated fetal calf serum were considered non-sensitized, and their phagocytosis occurred via the pattern-recognition receptors of phagocytes [17].

\section{Nitro blue tetrazolium slide test}

The nitro blue tetrazolium (NBT) test evaluated the ability to generate toxic oxygen radicals (superoxide anion $/ \mathrm{O}_{2}^{-}$) that are capable of reducing the compound NBT to an insoluble form, formazan, which is identified via optical microscopy as a blue color in the cytoplasm of the cell [18]. The amount of reduced NBT is directly proportional to the amount of oxygen radicals $\left(\mathrm{O}_{2}^{-}\right)$produced by the phagocytes. After the phagocytes were adhered, cells from the control and asthmatic children were incubated with $0.05 \%$ NBT solution in Hanks-Tris solution (Sigma, St Louis, MO, USA) for $20 \mathrm{~min}$ at $37^{\circ} \mathrm{C}$ in a humidified chamber. The slides were then washed, fixed with methanol and stained with a $1.4 \%$ safranin and $28.6 \%$ glycerol. The percentage of phagocytes that contained reduced cytoplasmic NBT was assessed by optical microscopy, and the source of the individual preparations was revealed only at the end of the evaluation [18].

\section{Statistical analysis}

The data were previously tested with Bartlett's test for equal variances and the Kolmogorov-Smirnov test for normality of distribution. The Mann-Whitney test was used to compare two non-normal samples. The Kruskal-Wallis test, followed by Dunn's method, was used to compare multiple non-normal samples. Spearman's test was used to evaluate the correlation between samples. The chi-square test was used to compare proportions. For homogeneity of data presentation, all values were expressed as the median, quartiles and extremes, and outlier values were indicated. Differences and correlations with a two-tailed value of $\mathrm{p}<0.05$ were considered statistically significant. The Prism 5 software package (GraphPad, San Diego, CA, USA) was used for statistical tests and graphical presentation of the data.

\section{Results}

\section{Clinical and demographic characteristics}

The characteristics of the children enrolled in the study and the clinical outcomes during 3 and 6 months of corticosteroid treatment are summarized in Tables 1 and 2 .

Table 2 Clinical characteristics of asthmatic children before, 3 and 6 months after inhaled corticosteroid therapy

\begin{tabular}{|c|c|c|c|c|}
\hline Parameters & Before & 3 months & 6 months & Test $p$ \\
\hline PEF (\%) $($ mean $\pm S D)$ & & & & ANOVA \\
\hline $\mathrm{mPA}$ & $81.2 \pm 17.3$ & $90.6 \pm 23.6$ & $99.2 \pm 18.4$ & $p<0.05^{*}$ \\
\hline MPA & $75.6 \pm 15.3$ & $79.3 \pm 16.8$ & $86.3 \pm 18.3$ & $p<0.05^{*}$ \\
\hline SPA & $65.6 \pm 12.0$ & $72.8 \pm 17.0$ & $77.9 \pm 19.8$ & $p>0.05$ \\
\hline \multicolumn{5}{|l|}{$\mathrm{BMI}\left(\mathrm{Kg} / \mathrm{m}^{2}\right)($ mean $\pm \mathrm{SD})$} \\
\hline $\mathrm{mPA}$ & $51.9 \pm 34.3$ & $45.2 \pm 32.2$ & $43.4 \pm 37.5$ & \multirow[t]{3}{*}{ Kruskal-Wallis $p>0.05$} \\
\hline MPA & $47.4 \pm 31.2$ & $50.5 \pm 31.5$ & $50.0 \pm 30.5$ & \\
\hline SPA & $63.7 \pm 32.5$ & $61.8 \pm 29.6$ & $63.2 \pm 29.5$ & \\
\hline \multicolumn{5}{|l|}{ ACT n (\%) } \\
\hline \multicolumn{5}{|l|}{$\mathrm{mPA}$} \\
\hline$\geq 25$ & 0/23 (0\%) & $1 / 23(4.3 \%)$ & 4/22 (18.2\%) & Chi-square \\
\hline $20-24^{* *}$ & $11 / 23(47.8 \%)$ & 19/23 (82.6\%) & 16/22 (72.7\%) & $p<0.05$ \\
\hline$<20^{* * *}$ & $12 / 23(52.2 \%)$ & $3 / 23(13.0 \%)$ & $2 / 22(9.1 \%)$ & \\
\hline \multicolumn{5}{|l|}{ MPA } \\
\hline$\geq 25$ & 0/20 0\%) & $1 / 20(5 \%)$ & $3 / 20(15 \%)$ & Chi-square \\
\hline $20-24^{* *}$ & $2 / 20(10 \%)$ & $7 / 20(35 \%)$ & $10 / 20(50.0 \%)$ & $p<0.05$ \\
\hline$<20^{* * *}$ & 18/20 (90\%) & $12 / 20(60 \%)$ & $7 / 20$ (35.0\%) & \\
\hline \multicolumn{5}{|l|}{ SPA } \\
\hline$\geq 25$ & 0/14 (0\%) & 0/14 (0\%) & $0 / 14(0 \%)$ & Chi-square \\
\hline $20-24$ & $2 / 14(14.3 \%)$ & 3/14 (21.4\%) & 4/14 (28.6\%) & $p>0.05$ \\
\hline$<20$ & $12 / 14(85.7 \%)$ & $11 / 14(78.57 \%)$ & $10 / 14(71.4 \%)$ & \\
\hline
\end{tabular}

PEF Peak Expiratory Flow, BMI Body Mass Index (percentile), ACT Asthma Control Test, mPA mild persistent asthma, MPA moderate persistent asthma, $S P A$ severe persistent asthma, ${ }^{*} 6 \mathrm{~m}>$ before $^{* *} 3 \mathrm{~m}$ and $6 \mathrm{~m}>$ before ${ }^{* *} 3 \mathrm{~m}$ and $6 \mathrm{~m}<$ before. 
Children from the control group had the mean age 3 years older than the asthmatic children $(10.7 \pm 2.10$ years versus $7.6 \pm 3.4$ years; $\mathrm{p}=0.001$, $t$ test), but no difference was observed based on gender between the children with or without asthma ( $\mathrm{p}=0.6$, Chi-square test). To exclude a possible influence of age as an independent confounding variable on the results of phagocyte functions, the univariate correlation between age and monocyte and neutrophil phagocytic indices and \% NBT reduction for healthy control and asthmatic children was tested. No correlation was observed between age and these phagocyte functions (Spearman's test, $\mathrm{p}>0.05$ ). Therefore, no adjustment of results of phagocyte functions for age was done. Furthermore, previous observations had shown that there are not differences among preschool children, schoolchildren and adolescent phagocyte functions.

No statistically significant difference was observed between groups for leukocytes, except for eosinophils. The median of the number of eosinophils in peripheral blood was significantly higher in asthmatic children than healthy control (245 for the control group and 460, 635, and 487 for $\mathrm{mPA}, \mathrm{MPA}$ and SPA groups, respectively, before ICT; $\mathrm{p}=0.003$, ANOVA) (Table 1).

ACT and PEF showed the clinical improve after 3 and 6 months follow up (Tables 1 and 2).

In the 3 months evaluation, the phagocyte tests was done in 50 children $(\mathrm{n}=50)$, and in the 6 months evaluation, the phagocyte tests of was done in 47 children $(n=47)$.
No difference was observed between the phagocytic indices in children with different clinical severities of persistent asthma

To determine whether the severity of persistent asthma influenced the phagocytic capacity of monocytes and neutrophils, the phagocytic indices of monocytes and neutrophils from children with different severities of asthma were compared. All groups of asthmatic children showed a lower phagocytic index than the healthy control children; however, no difference was observed between the children with mild, moderate or severe persistent asthma (KruskalWallis test followed by Dunn's method, $\mathrm{p}<0.01$ ) (Figure 1).

Monocytes and neutrophils from children with asthma showed less phagocytosis through pattern molecular receptors, and treatment with ICS for 6 months was not sufficient to normalize phagocytic function

To assess the influence of inhaled corticosteroids on phagocytosis, the phagocytic capacity of monocytes and neutrophils from children with different severities of asthma was compared before and after corticosteroid treatment.

Using non-sensitized S. cerevisiae, the monocytes of children with mild, moderate and severe persistent asthma showed a lower phagocytic index than healthy children. The median phagocytic index of the monocytes from children with asthma from all groups prior to treatment was significantly lower than that in the control healthy children
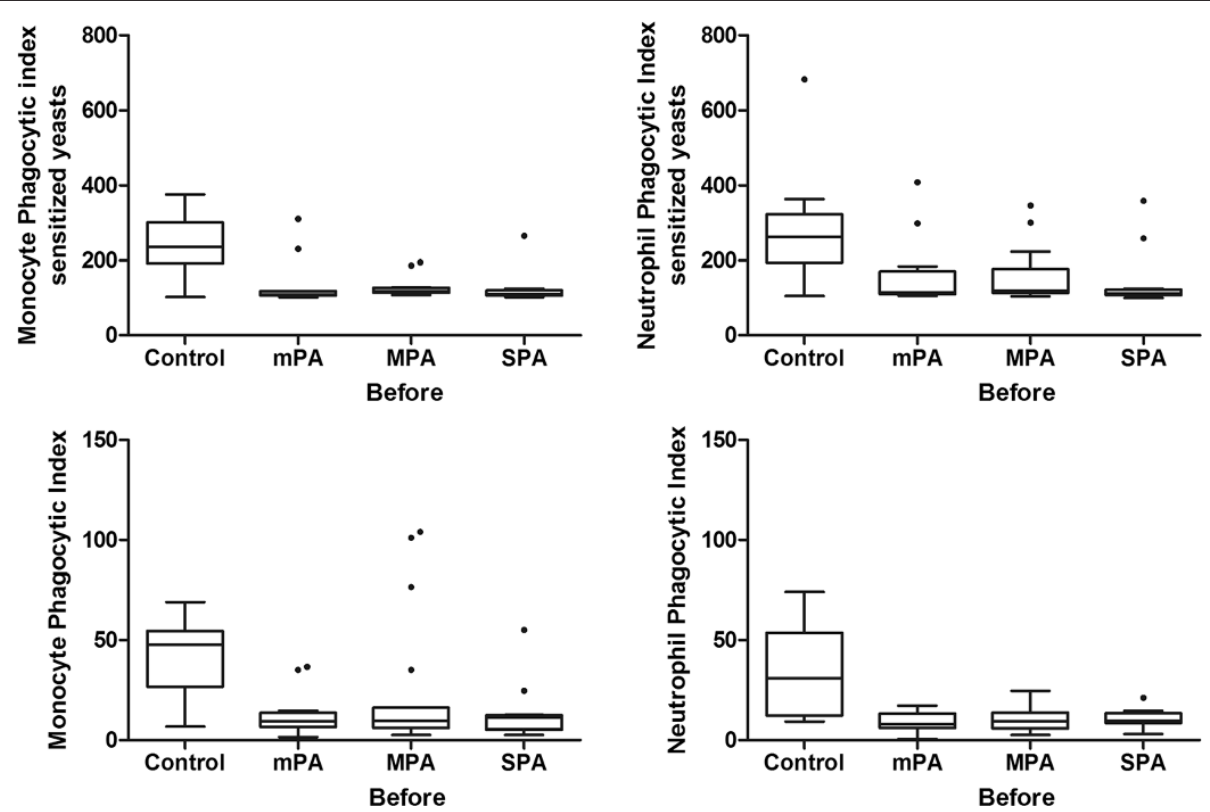

Figure 1 In vitro evaluation of the phagocytic indices of monocytes (left) and neutrophils (right) in individuals with mild persistent asthma (mPA), moderate persistent asthma (MPA) and severe persistent asthma (SPA) before treatment and in normal control children using $2.5 \times 10^{5}$ yeast cells per well. For the top panels, sensitized yeasts were used. For the bottom panels, non-sensitized yeasts were used. Statistical analyses showed that the median value of all groups of asthmatic children was lower than that of the healthy control children; however, no difference was observed between the groups with mild, moderate and severe persistent asthma (Kruskal-Wallis test followed by the Dunn's method). The data are expressed as the median, quartile and extreme, and outlier values are marked. 
( $\mathrm{p}<0.05$, Mann-Whitney test) (Figure 2C, F, I), and this deficiency was caused by lower quantitative involvement of phagocytes in phagocytosis when compared to the control healthy children $(\mathrm{p}<0.05$, Mann-Whitney test) (Figure $2 \mathrm{~B}$, $\mathrm{E}, \mathrm{H})$, because there was no difference in the median number of phagocytosed $S$. cerevisiae per monocyte between the control and asthmatic children ( $>00.05$, Mann-Whitney test) (Figure 2A, D, G). Subsequent to the inhaled corticosteroid treatment of children with asthma, there were no differences among the groups for phagocytic index, percentage of monocytes engaged in phagocytosis and the number of yeast cells phagocytosed over six months of treatment (Figure 2).

Similar results were observed for the neutrophils. Prior to the inhaled corticosteroid treatment, the neutrophils from children with mild, moderate and severe asthma also exhibited significantly lower phagocytic indices $(\mathrm{p}<0.05$, Mann-Whitney test; Figure 3C, F, I) and lower proportions of cells involved in phagocytosis ( $p<0.05$, MannWhiney test; Figure $3 \mathrm{~B}, \mathrm{E}, \mathrm{H}$ ) than the neutrophils from control healthy children for non-sensitized yeast cells (Figure 3). ICS therapy for 3 and 6 months did not modify phagocytosis by the neutrophils (Figure 3 ).

\section{Monocytes and neutrophils from children with asthma showed less phagocytosis of opsonized yeast cells via complement and immunoglobulin receptors, and} treatment with inhaled corticosteroids (ICS) for 6 months was not sufficient to normalize phagocyte function

Using sensitized S. cerevisiae, the monocytes and neutrophils from children with mild, moderate and severe persistent asthma also showed lower phagocytic indices than the
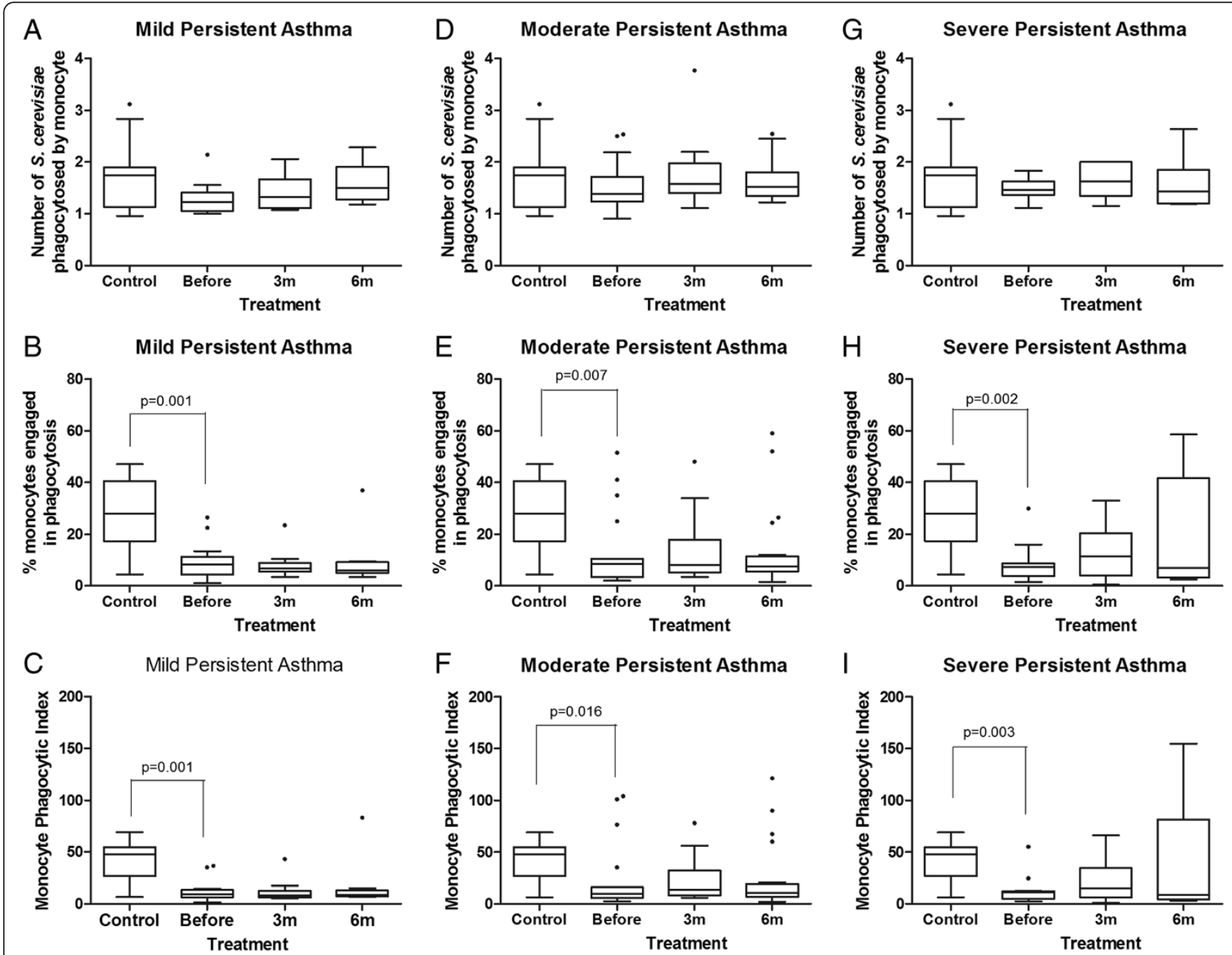

Figure 2 Influence of inhaled corticosteroid treatment on the phagocytic capacity of monocytes via pattern-recognition receptors in children with mild, moderate and severe persistent asthma before and during the $3^{\text {rd }}$ and $6^{\text {th }}$ months of treatment compared to healthy controls using non-sensitized Saccharomyces cerevisiae. The data are expressed as the median, quartile and extreme values. The outlier data are indicated. Top: average number of $\mathbf{S}$. cerevisiae yeast cells ingested by phagocytosing monocytes (A, D, G); Middle: percentage of monocytes engaged in phagocytosis $(\mathbf{B}, \mathbf{E}, \mathbf{H})$; Bottom: monocyte phagocytic index $(\mathbf{C}, \mathbf{F}, \mathbf{I})$. The statistical differences are marked in the graphics and in text. 


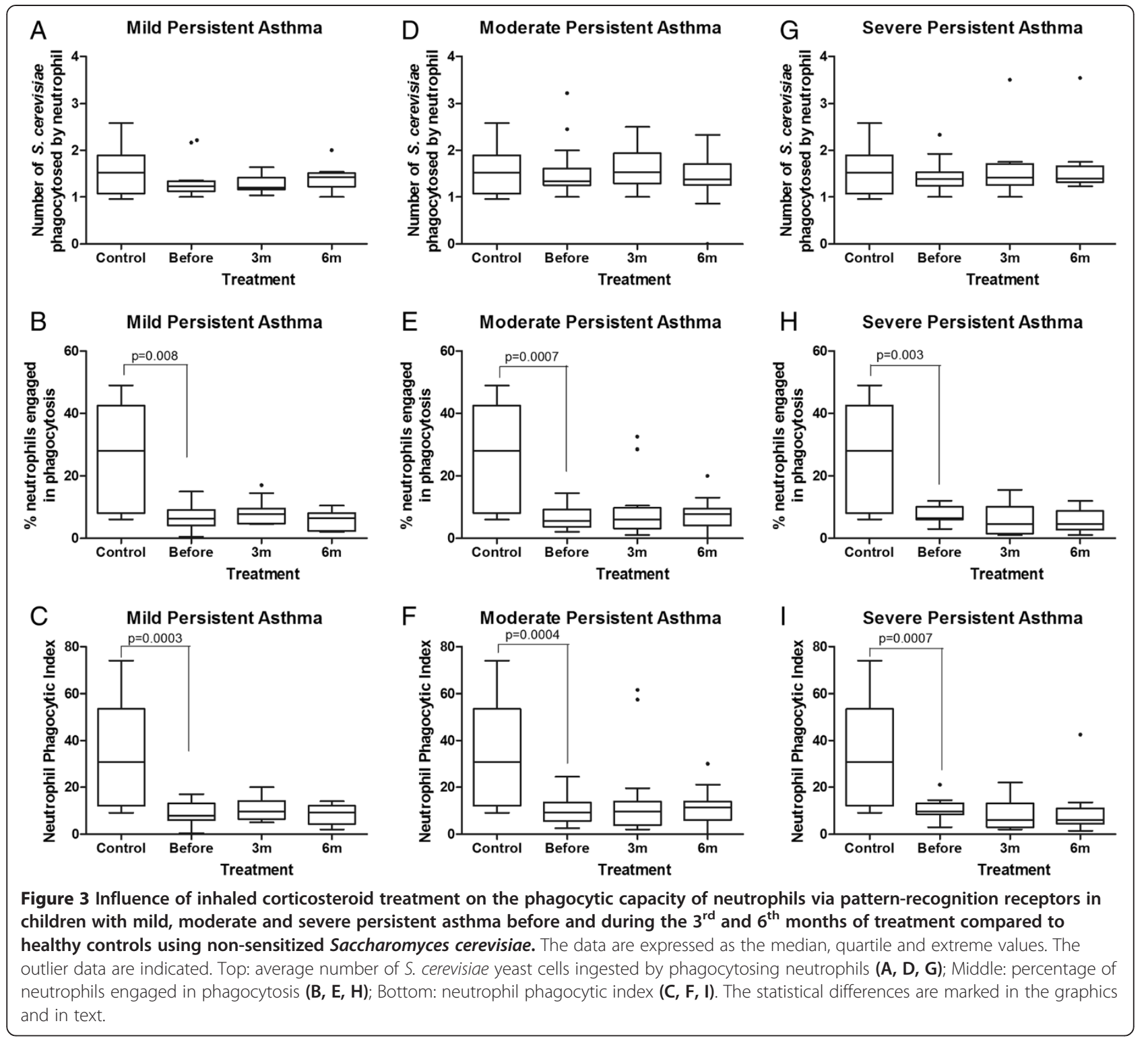

healthy children. The median phagocytic indices of monocytes and neutrophils from children with asthma from all groups prior to treatment was significantly lower than the healthy control children $(\mathrm{p}<0.05$, Mann-Whitney test; Figure 4C, F, I). This result differed from that obtained using the non-sensitized yeasts. The decrease in monocyte and neutrophil phagocytic index was caused by both the lower quantitative involvement of the phagocytes in phagocytosis when compared to the healthy control children $(\mathrm{p}<0.05$, Mann-Whitney test; Figure 4B, E, H; Figure 5B, $\mathrm{E}, \mathrm{H})$, and the smaller number of particles phagocytosed per monocyte or neutrophil ( $p>0.05$, Mann-Whitney test, Figure 4A, D, G; Figure 5A, D, G). Moreover, ICS therapy for 6 months was not able to modify the phagocytic index, the percentage of monocytes or neutrophils engaged in phagocytosis or the number of phagocytosed yeast (Figures 4 and 5).

\section{Influence of inhaled corticosteroids on superoxide anion production}

The difference between the control and asthmatic children was statistically significant only for the children with mild persistent asthma (Figure 6A, D). When the \% reduction of NBT was assessed either with $(\mathrm{p}<0.02$, Mann-Whitney test, Figure $6 \mathrm{~A})$ or without stimulation $(\mathrm{p}=0.01$, Mann-Whitney test, Figure 6D), the capacity to produce superoxide anions was decreased in the asthmatic children before treatment. Treatment with inhaled corticosteroids differentially influenced the production of this oxygen radical. When assessed without stimuli, there was an 


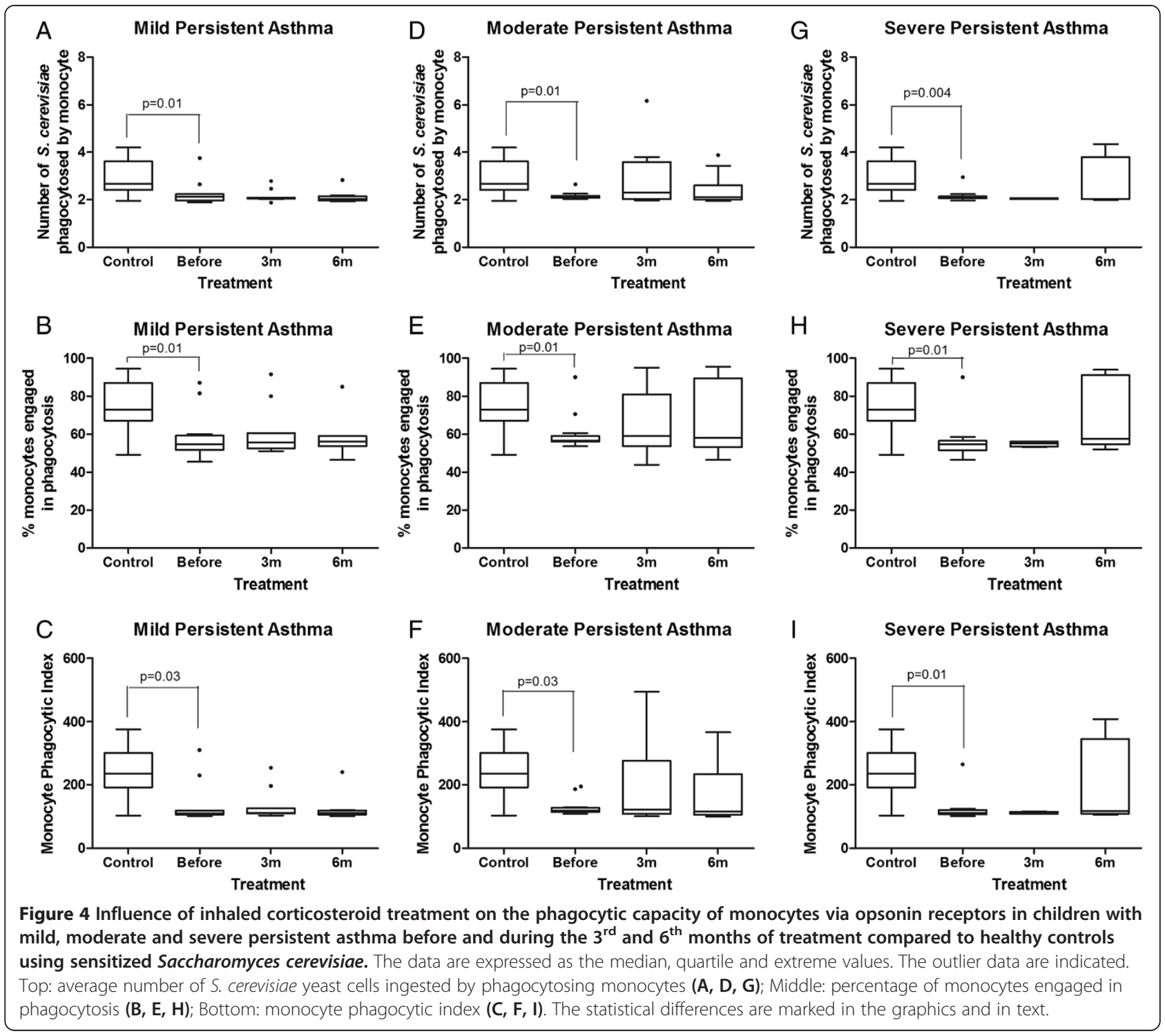

increase in the \% reduction of NBT after $6 \mathrm{~m}$ of treatment ( $<<0.05$, Kruskal-Wallis test followed by Dunn's method, Figure 6D). However, when the \% NBT reduction was assessed after phagocytosis stimulation, there was decreased production of superoxide anions after 3 and $6 \mathrm{~m}$ of follow-up ( $<<0.05$, Kruskal-Wallis test followed by Dunn's method) (Figure 6A).

\section{Discussion}

This prospective study evaluated for the first time the influence of 3 and 6 months of treatment with inhaled corticosteroids on the neutrophil and monocyte functions of asthmatic children. Our data showed that 6 months of ICS was not sufficient to return the decreased phagocyte functions to normal in the asthmatic children. Although 6 months of treatment caused some improvement in the clinical parameters, such as an increase in peak expiratory flow, and a significant increase in percentage of children with mild and moderate persistent asthma showing ACT > 25 and ACT $=20-24$, (Table 2), no concomitant recovery of phagocyte function was observed.

Our data showed that the phagocytic capacity of monocytes and neutrophils in children with mild, moderate and severe persistent asthma was lower than in the healthy control children. A significant decrease in phagocytosis by monocytes and neutrophils $[19,20]$, bronchial macrophages [21] and alveolar macrophages [11] has also been shown in asthmatic individuals.

Our data demonstrated that the severity of asthma did not influence the immunodeficiency in phagocytes. The phagocytic indices of the neutrophils and monocytes from the children with mild, moderate or severe persistent asthma were decreased, and there were no differences among these groups (Figure 1). Our data differed from those 


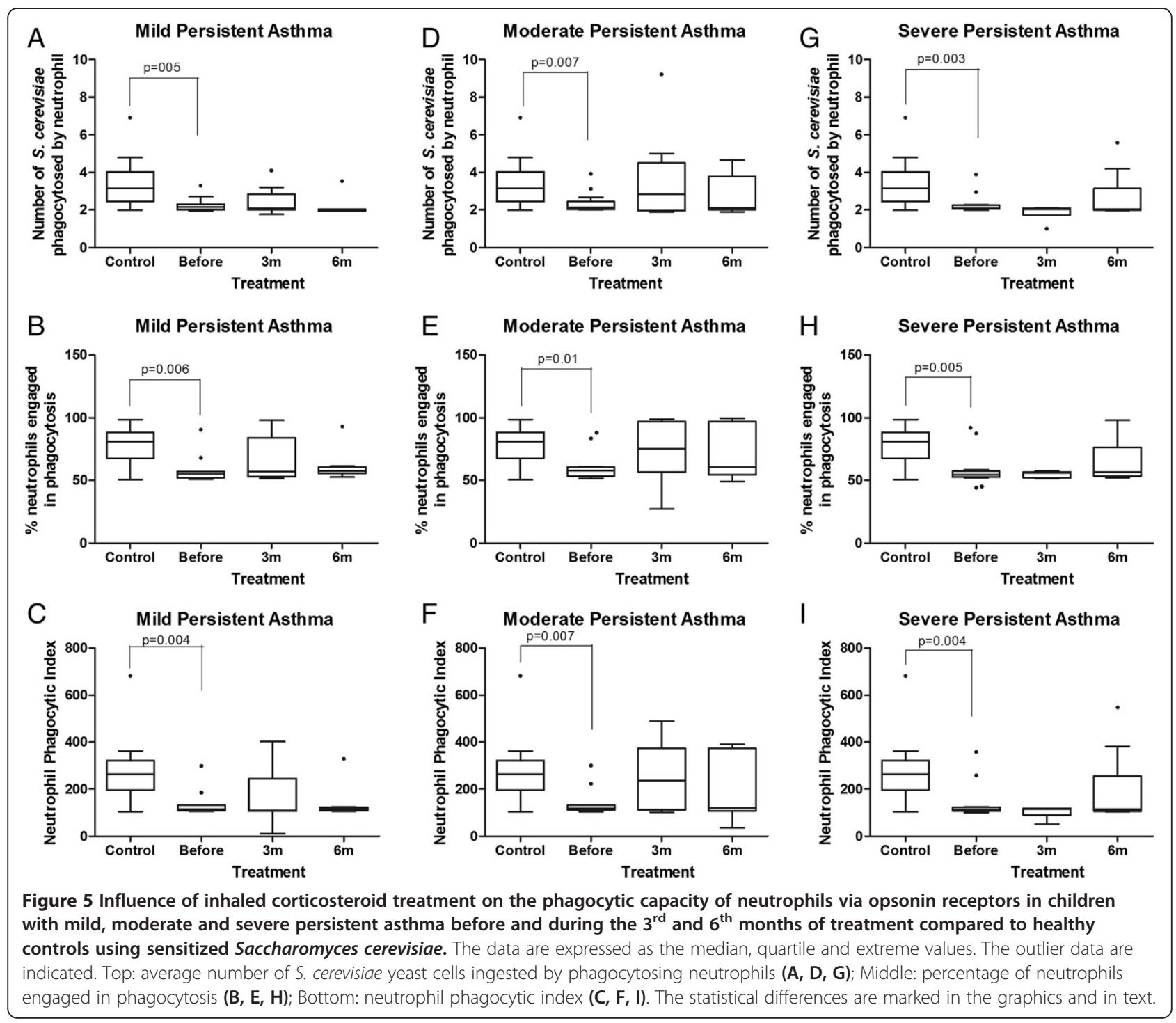

of Fitzpatrick et al. [11], who observed greater deficiencies in severe asthma patients. However, Alexis et al. [21] also showed decreased phagocytosis in mild asthma patients, whereas Lay et al. [22] observed increased phagocytosis by macrophages obtained from the sputum of asthma patients. The differences between our observations and those of other researchers who have assessed phagocytosis in asthma are most likely the result of the following factors: differences in the clinical form of the disease, the severity of the disease, the age of individuals, the treatment used, the stimuli used, the source of phagocytes tested, the cell type assessed, and genetic differences between individuals [11,19-22].

The deficiency in phagocytosis was evident when phagocytosis was assessed either through pathogen associated molecular pattern receptors (non-sensitized) or through complement and antibody receptors (sensitized). To be able to phagocytose, the phagocyte needs to move toward the $S$. cerevisiae and ingest the particle. Because the reduction in phagocytosis was attributable to the decreased quantitative involvement of the phagocytes in phagocytosis, it is possible that phagocytes in asthmatic children had decreased capacity to move toward the yeast. In fact, it was previously shown that $\beta 2$-agonists and glucocorticoids, which are commonly used for the treatment of obstructive lung diseases, influence chemokine release and receptor sensitivity and, consequently, the chemotaxis of these cells [23].

When sensitized phagocytosis through FcyR and complement receptors was assessed, the deficiency was evidenced as both to the decreased quantitative involvement of the phagocytes in phagocytosis and the decreased number of yeast cells phagocytosed. The reasons for this effect are not clear; however, one possible explanation is a decrease in the expression of receptors for complement and/or $F_{c} \gamma R$ in the membranes of the monocytes and neutrophils from asthma patients. Alexis et al. [19] found a significant correlation 


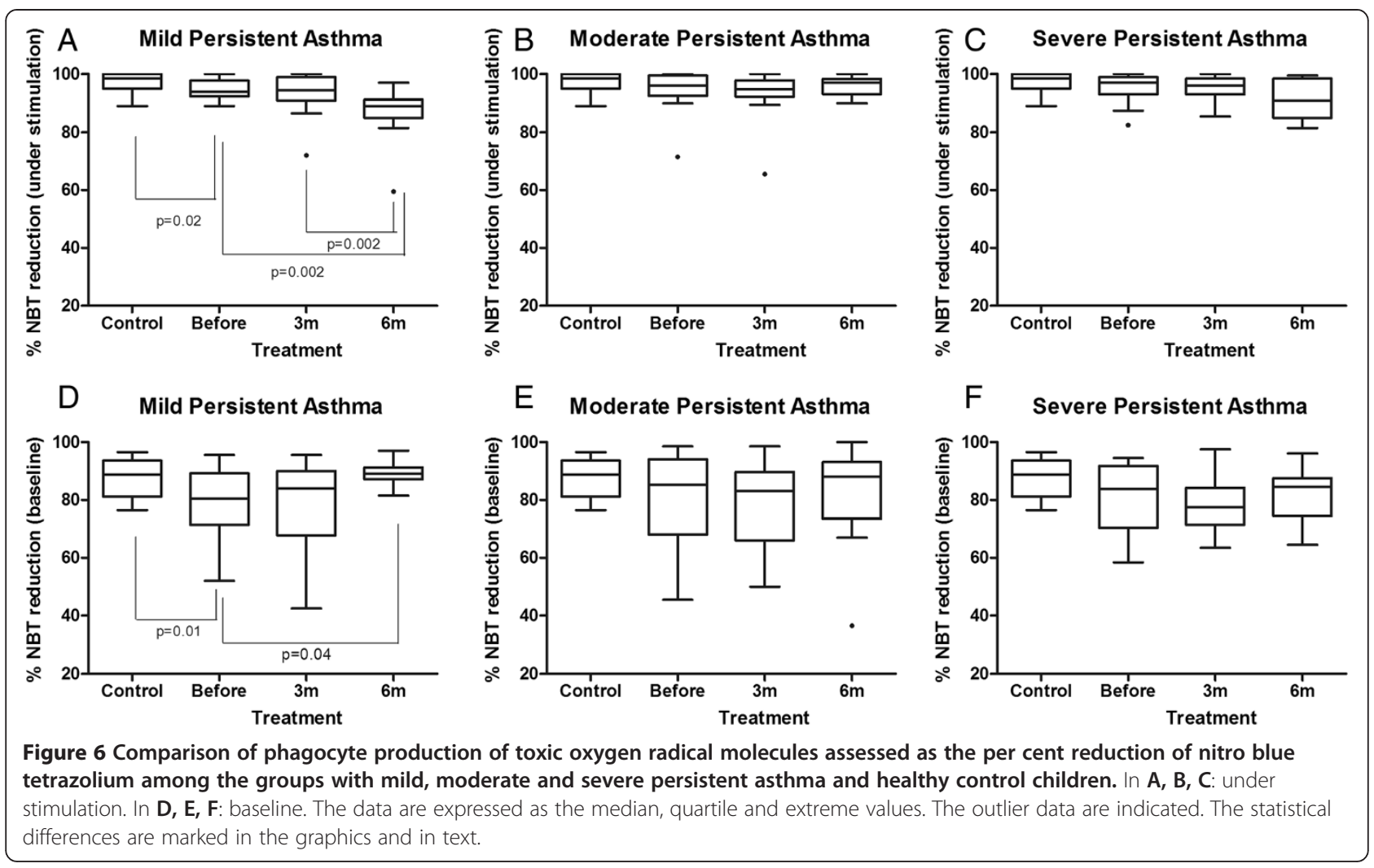

between the expression of $\mathrm{CD} 64(\mathrm{~F} c \gamma \mathrm{R})$ and phagocytosis by bronchial macrophages from asthmatic individuals and the reduced expression of CD11b, a component of the CR3 receptor, and phagocytosis in sputum and in neutrophils and monocytes from asthmatics.

Although there was clinical improvement in asthma with corticosteroid therapy, we can hypothesize that the effect of the drug on phagocytes decreasing the phagocytosis may have contributed to the insufficient recovery of phagocytosis after six months of clinical follow-up. In fact, corticosteroids decrease phagocytosis by monocytes and the production of inflammatory cytokines $[3,13]$. Corticosteroids also increase the production of IL-10, a cytokine that deactivates monocytes $[3,5]$. Therefore, it is possible that phagocytosis did not return to normal because of the action exerted by the corticosteroids on the phagocytes. Another possibility to explain this lack of response of phagocytes to ICT by us observed might be that the insufficient recovery of immune alterations remained downmodulating phagocyte function.

Superoxide anion production, which was assessed as the per cent reduction of nitro blue tetrazolium, by phagocytes from asthmatic and control children was statistically decreased only for children with mild persistent asthma. The response to ICS after 6 months of treatment was different when assessed at baseline or after stimulation. Inhaled corticosteroids increased the per cent NBT reduction only when assessed without stimulation; however, these values were to the values of healthy, normal children, they did not exceed the values observed in normal children. However, when superoxide anion production was evaluated after stimulation with sensitized S. cerevisiae, there was a decrease in superoxide anion production. It is possible that decreased phagocytosis may have played a role in the decreased superoxide anion production by these cells.

Generation of radical oxygen species occurs through several enzymatic pathways or chemical process that are essential in many physiological reactions such as killing invading pathogens, and takes place in every cell. However, increased levels of ROS can produce harmful pathophysiological disorders that damage DNA, lipids, proteins, and carbohydrates, leading to enhanced inflammatory response [24]. Oxidative stress has been proven to affect smooth muscle contraction, induce airway hyperresponsiveness, and increase mucus secretion, and excessive ROS production can trigger key alterations, leading to an antioxidant-oxidant imbalance that has been shown in patients with asthma and differ significantly according to severity of the disease [24-26]. It was also observed that resting or stimulated phagocytes may produce differently reactive oxygen species that depends on the disease form [27]. Predominance of enhancement of ROS has been observed in asthma [25-27]. The differences between our 
observations and other researchers who have assessed ROS in asthma are most likely the result of the type of ROS evaluated, the cell type assessed and differences in the clinical form and severity of the disease.

Influence of treatment with corticoid has been also evaluated. It was observed that budesonide reduced the oxidative stress in the in guinea pig [28] and ICT was able to influence the production of NADP oxidase in a dose dependent manner [29]. Treatment with glucocorticosteroids as antioxidants has been suggested, based in its antioxidants properties [30]. We only observed influence of ICT in mild persistent asthma. A possible explanation by the different response observed by us is the type of ROS analyzed and the cell tested.

Oxidative injury leads to increased lipid peroxidation, increased airway reactivity and secretions, production of chemoattractant molecules, and increased vascular permeability [31-33], which collectively lead to the augmentation of the existing inflammation that is a hallmark of asthma. Therefore, lower oxygen radical production in asthma may contribute to the decreased immunopathogenesis by these molecules in asthma. On the other hand, a lower production of superoxide anions can lead to immunodeficiency and may hinder the immune defense against infectious agents.

Although corticosteroids are considered the first-line drugs for asthma therapy, the number of children that meet the clinical control evaluated by ACT $(>25)$ in children that were followed-up for $6 \mathrm{~m}$ in this study was small. Significant variability in the response to inhaled corticosteroids for persistent asthma has been shown [34], and uncontrolled asthma occurs in more than 50\% of children who receive treatment with low-dose inhaled corticosteroids [35]. It is possible that this lower clinical response occurred because there was a high percentage of moderate and severe persistent asthma among the assessed children. Furthermore, the children were treated at home, and although adherence to treatment was encouraged in all clinical evaluation, there is no assurance regarding the regular use of corticosteroids during the follow-up period. This uncertainty is a limitation of our study. The lower age of asthmatic children than healthy control children was also a limitation, however, we had already showed that there are not differences in phagocytosis between children higher 2 years old [16]. Some children received different ICS (budesonide or fluticasone) that is a limitation of this study. Another possible limitation of our study is the fact that phagocytosis was assessed in phagocytes obtained from peripheral blood and not from induced-sputum or bronchoalveolar lavage in order to evaluate directly the effects of disease and treatment on the phagocytic function at the local level. However, asthma is a systemic disease showing several cytokines and other molecules enhanced in peripheral blood that may influence functions of cells of immune system and phagocytosis and might be influenced by corticoid treatment as we observed in this paper. In support to this consideration, morphological changes in eosinophils obtained from peripheral blood markedly correlate with the disease and may indicate the clinical severity of the acute exacerbation [36], corroborating that blood cells may also be influenced by the immune response occurring in asthmatic individuals. Furthermore, sputum induction can be challenging for young children [37], and the influence on phagocytosis of mucus [38], enzymes [39] and microorganisms [40] presents in sputum couldn't be excluded, in addition to the ethical limitation to evaluate phagocytosis in phagocytes from bronchoalveolar lavage.

\section{Conclusions}

Our findings may broaden the understanding of the influence of inhaled corticosteroids on phagocyte functions. Our data showed that asthmatic children followed up for 6 months in treatment with ICT didn't modify decreased phagocytosis. However, the baseline production of superoxide anions by phagocytes was normalized. Because phagocytes actively participate in both the lesion and the defense of the lung in asthma, it is possible that the result of these opposing effects was beneficial to treated patients because there was some clinical improvement. Furthermore, the reduction in lesions caused by oxygen radicals may have been beneficial to the treated children.

\section{Abbreviations}

ICT: Inhaled corticosteroid therapy; ACT: Asthma control test; LABA: Longacting $\beta_{2}$-agonist; PBS: Phosphate-buffered saline; FCS: Fetal calf serum; NBT: Nitro blue tetrazolium; BMI: Body mass index; mPA: Mild persistent asthma; MPA: Moderate persistent asthma; SPA: Severe persistent asthma.

\section{Competing interests}

The authors report no conflict of interests. The authors alone are responsible for the content of the paper. The authors used a copy-editing service for language revision.

\section{Authors' contributions}

CLFS-M and MIMJ designed the study protocol. CLFS-M and SCC performed the experiments. CLFS-M performed the clinical assessment. CLFS-M and MIMJ analyzed and interpreted the data. CLFS-M, SCC and MIMJ wrote the manuscript. MIMJ revised the manuscript. All authors read, revised and approved the final manuscript.

\section{Acknowledgements}

MIM-J is an investigator supported by the Conselho Nacional de Desenvolvimento Científico e Tecnológico (CNPq), Brazil (process number 304015/2010-5).

\section{Author details}

'Laboratory of Cellular Immunology, Pathology, Faculty of Medicine, Campus Darcy Ribeiro, Asa Norte, University of Brasilia, Brasilia, DF 70.910-900, Brazil. ${ }^{2}$ Department of Paediatric, Faculty of Medicine, Campus Darcy Ribeiro, Asa Norte, University of Brasilia, Brasilia, DF 70.910-900, Brazil. ${ }^{3}$ Paediatric Service, University Hospital of Brasilia, Brasilia, DF 70.910-900, Brazil.

Received: 19 April 2013 Accepted: 14 August 2013

Published: 30 August 2013 


\section{References}

1. Bateman ED, Hurd SS, Barnes PJ, Bousquet J, Drazen JM, FitzGerald M, Gibson P, Ohta K, O'Byrne P, Pedersen SE, Pizzichini E, Sullivan SD, Wenzel $\mathrm{SE}, \mathrm{Zar} H \mathrm{HJ}$ : Global strategy for asthma management and prevention: GINA executive summary. Eur Respir J 2008, 31:143-178.

2. Papadopoulos NG, Arakawa H, Carlsen KH, Custovic A, Gern J, Lemanske $R$ Le Souef VP, Mäkelä M, Roberts G, Wong G, Zar H, Akdis CA, Bacharier LB, Baraldi E, van Bever HP, de Blic J, Boner A, Burks W, Casale TB, CastroRodriguez JA, Chen YZ, El-Gamal YM, Everard ML, Frischer T, Geller M, Gereda J, Goh DY, Guilbert TW, Hedlin G, Heymann PW, et al: International consensus on (ICON) pediatric asthma. Allergy 2012, 67:976-997.

3. Barnes PJ: How corticosteroids control inflammation: Quintiles Prize Lecture 2005. Br J Pharmacol 2006, 148:245-254.

4. Barnes PJ, Pedersen S, Busse WW: Efficacy and safety of inhaled corticosteroids. New developments. Am J Respir Crit Care Med 1998, 157(Suppl):1-53.

5. Barnes PJ: Glucocorticosteroids: current and future directions. $\mathrm{Br} J$ Pharmacol 2011, 163:29-43.

6. GINA Science Committee: Global Strategy for asthma management and prevention. Updated 2012. [http://www.ginasthma.com]

7. O'Byrne PM, Pedersen S, Busse WW, Tan WC, Chen Y-Z, Ohlsson SV, Ullman A, Lamm CJ, Pauwels RA: Effects of early intervention with inhaled budesonide on lung function in newly diagnosed asthma. Chest 2006, 129:1478-1485.

8. Dahl R: Systemic side effects of inhaled corticosteroids in patients with asthma. Respir Med 2006, 100:1307-1317.

9. Saffar AS, Ashdown $\mathrm{H}$, Gounni AS: The molecular mechanisms of glucocorticoids-mediated neutrophil survival. Curr Drug Targets 2011, 12:556-562.

10. Khanduja KL, Kaushik G, Khanduja S, Pathak CM, Laldinpuii J, Behera D: Corticosteroids affect nitric oxide generation, total free radicals production, and nitric oxide synthase activity in monocytes of asthmatic patients. Mol Cell Biochem 2011, 346:31-37.

11. Fitzpatrick AM, Holguin F, Teague WG, Brown LA: Alveolar macrophage phagocytosis is impaired in children with poorly controlled asthma. J Allergy Clin Immunol 2008, 121:1372-1378.

12. Rinehart JJ, Balcerzak SP, Sagone AL, LoBluglio AF: Effects of corticosteroids on human monocyte function. J Clin Invest 1974, 54:1337-1343.

13. Donnelly LE, Barnes PJ: Defective phagocytosis in airways disease. Chest 2012, 141:1055-1062.

14. Busse WW, Boushey HA, Camargo CA Jr, Evans D, Foggs MB, Janson SL, Kelly HW, Lemanske RF, Martinez FD, Meyer RJ, Nelson HS, Platts-Mills TAE, Schatz M, Gail Shapiro G, Stoloff S, Szefler SJ, Weiss ST, Yawn BP: Guidelines for the Diagnosis and Management of Asthma. National Asthma Education and Prevention Program (NAEPP), National Heart, Lung, and Blood Institute (NHLBI), National Institutes of Health; 2007:1-400. http://www.nhlbi.nih.gov/ guidelines/asthma/asthgdln.pdf.

15. Nathan RA, Sorkness CA, Kosinski M, Schatz M, Li JT, Marcus P, Murray JJ, Pendergraft TB: Development of the asthma control test: a survey for assessing asthma. J Allergy Clin Immunol 2004, 113:59-65.

16. Muniz-Junqueira MI, Peçanha LMF, Silva-Filho VL, Cardoso MCA, Tosta CE: Assessment of post-natal maturation of the phagocytic function of neutrophils and monocytes using a novel microtechnique. Clin Diagn Lab Immunol 2003, 10:1096-1102

17. Brown GD: Innate antifungal immunity: the key role of phagocytes. Annu Rev Immunol 2011, 29:1-21.

18. Muniz-Junqueira MI, Paula-Coelho VN: Meglumine antimonate directly increases phagocytosis, superoxide anion and TNF-a production, but only via TNF-a it indirectly increases nitric oxide production by phagocytes of healthy individuals, in vitro. Int Immunopharmacol 2008 8:1633-1638.

19. Alexis NE, Eldridge MW, Peden DB: Effect of inhaled endotoxin on airway and circulating inflammatory cell phagocytosis and CD11b expression in atopic asthmatic subjects. J Allergy Clin Immunol 2003, 112:353-361.

20. Lavinskiene S, Jeroch J, Malakaskas K, Bajoriuniene L, Jackute J, Sakalauskas R: Peripheral blood neutrophil activity during Dermatophagoides pteronyssinus-induced late-phase airway inflammation in patients with allergic rhinitis and asthma. Inflammation 2012, 35:1600-1609.

21. Alexis NE, Soukup J, Nierkens S, Becker S: Association between airway hyperreactivity and bronchial macrophage dysfunction in individuals with mild asthma. Am J Physiol Lung Cell Mol Physiol 2001, 280:L369-L375.

22. Lay JC, Alexis NE, Zeman KL, Peden DB, Bennett WD: In vivo uptake of inhaled particles by airway phagocytes is enhanced in patients with mild asthma compared with normal volunteers. Thorax 2009, 64:313-320.
23. Strandberg K, Blidberg K, Sahlander K, Palmberg L, Larsson K: Effect of formoterol and budesonide on chemokine release, chemokine receptor expression and chemotaxis in human neutrophils. Pulm Pharmacol Ther 2010, 23:316-323.

24. Zuo L, Otenbaker NP, Rose BA, Katherine S, Salisbury KS: Molecular mechanisms of reactive oxygen species-related pulmonary inflammation and asthma. Mol Immunol 2013, 56:57-63.

25. Ahmad A, Shameem M, Husain G: Relation of oxidant-antioxidant imbalance with disease progression in patients with asthma. Ann Thoracic Med 2012, 7:226-232.

26. Celik M, Tuncer A, Soyer OU, Sac, kesen C, Tanju Besler H, Kalayci O: Oxidative stress in the airways of children with asthma and allergic rhinitis. Pediatr Allergy Immunol 2012, 23:556-561.

27. Vachier I, Chanez P, Le Doucen C, Damon M, Descomps B, Godard P: Enhancement of reactive oxygen species formation in stable and unstable asthmatic patients. Eur Respir J 1994, 7:1585-1592.

28. Long F, Yan Wang Y, Oi H-H, Xin Zhou X, Xian-Oiao Jin X-Q: Rapid nongenomic effects of glucocorticoids on oxidative stress in a guinea pig model of asthma. Respirology 2008, 13:227-232.

29. Ökrös Z, Endreffy E, Novak Z, Maroti Z, Monostori P, Varga IS, Király A, Turi S: Changes in NADPH oxidase mRNA level can be detected in blood at inhaled corticosteroid treated asthmatic children. Life Sci 2012, 91:907-911.

30. Sadowskaa AM, Klebeb B, Germonpré P, De Backer WA: Glucocorticosteroids as antioxidants in treatment of asthma and COPD. New application for an old medication? Steroids 2007, 72:1-6.

31. Nadeem A, Chhabra SK, Masood A, Raj HG: Increased oxidative stress and altered levels of antioxidants in asthma. J Allergy Clin Immunol 2003, 111:72-78.

32. Barnes PJ: Reactive oxygen species and airway inflammation. Free Radic Biol Med 1990, 9:235-243

33. Birben E, Sahiner UM, Sackesen C, Erzurum S, Kalayci O: Oxidative stress and antioxidant defense. WAO J 2012, 5:9-19.

34. Szefler SJ, Martin RJ, King TS, Boushey HA, Cherniack RM, Chinchilli VM, Craig TJ, Dolovich M, Drazen JM, Fagan JK, Fahy JV, Fish JE, Ford JG, Israel E, Kiley J, Kraft M, Lazarus SC, Lemanske RF Jr, Mauger E, Peters SP, Sorkness CA: Significant variability in response to inhaled corticosteroids for persistent asthma. J Allergy Clin Immunol 2002, 109:410-418.

35. Sorkness CA, Lemanske RF Jr, Mauger DT, Boehmer SJ, Chinchilli VM, Martinez FD, Strunk RC, Szefler SJ, Zeiger RS, Bacharier LB, Bloomberg GR, Covar RA, Guilbert TW, Heldt G, Larsen G, Mellon MH, Morgan WJ, Moss MH, Spahn JD, Taussig LM: Long-term comparison of 3 controller regimens for mild-moderate persistent childhood asthma: the Pediatric Asthma Controller Trial. J Allergy Clin Immunol 2007, 119:64-72.

36. Muniz-Junqueira MI, Barbosa-Marques SM, Junqueira LF Jr: Morphological changes in eosinophils are reliable markers of the severity of an acute asthma exacerbation in children. Allergy 2013, 68:911-920.

37. Gogate S, Katial R: Pediatric biomarkers in asthma: exhaled nitric oxide, sputum eosinophils and leukotriene E4. Curr Opin Allergy Clin Immunol 2008, 8:154-157.

38. Voynow J, Rubin BK: Mucins, Mucus, and Sputum. Chest 2009, 135:505-512.

39. Maneechotesuwan K, Supawita S, Kasetsinsombat K, Wongkajornsilp A, Barnes PJ: Sputum indoleamine-2, 3-dioxygenase activity is increased in asthmatic airways by using inhaled corticosteroids. J Allergy Clin Immunol 2008, 121:43-50.

40. Marri PR, Stern DA, Wright AL, Dean Billheimer D, Martinez FD: Asthmaassociated differences in microbial composition of induced sputum. J Allergy Clin Immunol 2013, 131:346-352.

doi:10.1186/2045-7022-3-28

Cite this article as: da Silva-Martins et al:: Inhaled corticosteroid treatment for 6 months was not sufficient to normalize phagocytosis in asthmatic children. Clinical and Translational Allergy 2013 3:28. 